\title{
A RESPONSABILIDADE ALLEMAN PELA CONFLAGRAÇÃO EUROPA
}

\section{Conferencia pronunciada em Ribeirão Preto}

Não poderá deixar de ser um pouco enfadonha ésta conferencia, porque teremos de estudar, com calma, sem paixão, os documentos comprobatorios da culpa da Allemanha na actual conflagração, citando, com frequencia, o proprio texto das peças officiaes na linguagem fria desses documentos. Este processo de formação da culpa á grande criminosa, áquella que attentou contra a tranquillidade do genero humano, não deverá ser feito sinão friamente, como fica bem a um juiz. Nunca Julio Cesar iniciou uma campanha, sem primeiro justificar-se, e, em seus Commentarios á Guerra das Gallias, vemos transmittidos á posteridade, em linguagem lapidar, seus discursos aos inimigos, convencendo-os da justiça da causa romana, antes de os vencer com os fortes soldados da Republica de Tibre. A Allemanha mesmo, tem feito uma propaganda, mas sem respeito á verdade, em prol da defesa de seus actos bellicosos. $\mathrm{O}$ mais notavel esforço foi o do seu appello ao mundo civilizado, subscripto por 83 homens do escol daquella fatal sociedade, vendo-se entre as assignaturas as de Eucken, Hæckel, Fulda, Humperdinck, Dernburgo, Hauptmann e Lamprecht.

Lamentavel porém para a terra de Guilherme é que o appello dos intellectuaes não possa ser posto ao lado das orações de Cesar, modelos de concisão, de logica, de clareza, de estylo, e, sobretudo, persuasivas. Dizem os subditos do Kaiser, em seu manifesto á humanidade culta:

"Não é verdade que tenhamos violado a neutralidade da Belgica. Está provado que a França e a Inglaterra tinham decidido violal-a; e tambem que a Belgica a isso 
prestára seu consentimento. Fôra para nós um suicidio não havermos tomado a dianteira". Ora, meus concidadãos, isto faz-me lembrar certo delinquente que vi julgar, ha algum tempo, pelo tribunal do jury. Como lhe perguntasse o juiz qual o motivo por que assassinára, respondeu que sabia que a victima tencionava matal-o! Deste modo, não haverá mais delinquente. Si porque entendo eu que o Kaiser vae me matar, adquiro o direito de o assassinar, francamente não sei para que aprendi Direito, cinco annos, na Faculdade, lendo livros precisamente escriptos por alguns dos professores que assignaram o ridiculo manifesto. Foram esses homens, constituindo o escol da sociedade alleman, que escreveram: "Não é verdade que a lucta contra nosso intitulado militarismo allemão, deixe de ser lucta contra a civilização alleman. Sem o militarismo allemão, a civilização alleman teria desde muito tempo desapparecido". Ora o elogio do militarismo, como bem disse o New York Nation, parece que importa na defesa da escravidão. Nós americanos não podemos comprehender o serviço militar, sinão como sendo uma dura necessidade. O serviço militar imposto á mocidade, traz enormes sacrificios de dinheiro, augmento de impostos, afastamento do trabalho que gera a riqueza, e só póde ser admittido como representando um dever civico, uma obrigação que temos de acceitar para conservação da sociedade. Tudo porém deve fazer a cultura moderna para conseguir que a guerra se torne um fossil, para que cesse inteiramente a dura necessidade do regimen militar, que a imperfeita organização dos povos nos obriga a manter. $\mathrm{O}$ fanatismo allemão pelo regimen militar teria, como previu o lucido espirito de Renan, de levar á guerra actual. A celebre phrase do. Kronprinz sobre um ataque simulado, manifestando o desejo de que fosse real, foi prophetizada pelo grande genio de Renan, ao discorrer sobre as consequencias da predilecção do povo allemão para o militarismo. Armados, fortes, po- 
dendo impor sua vontade, sem cultura moral, unidos, naturalmente deveriam os allemães querer tirar proveito dessa sua superioridade em armas. Não contaram com a colligação de todos os povos cultos. Mas... vejamos a origem. da lucta. Como é sabido, não obstante ter Guilherme II dispensado os serviços de Bismarck, manteve sua politica brutal, cruel e de falsia. Conhecido é hoje (a Historia é um tremendo juiz!) que Bismarck chegou a falsificar telegrammas para empapar em sangue o solo da laboriosa e bella França. Guilherme II preparou-se cuidadosamente para, logo que obtivesse um pretexto, saltar sobre sua victima a generosa França. Foi o anno de 1913 de apprehensões: toda a Europa viu, com olhos suspeitos, o desenvolvimento da força naval e da terrestre no maldicto paiz que hoje attenta contra o socego de todo o mundo christão. A pretexto de que desejava celebrar o centenario da libertação da Allemanha do dominio do grande Napoleão, quiz o Kaiser dotar suas forças com um bilhão arrancado do povo laborioso, que tinha a infelicidade de o ter por senhor. Diga-se, de passo, que, na antiguidade, só havia, ensinam os mestres, em cada povo, um homem livre, que era o tyranno, sendo todos os outros membros da communhão social verdadeiros escravos, mas é licito modificar-se a ensinança, dizendo-se que, na Allemanha, a situação do povo é hoje a mesma que a dos victimados pelos despotas nos tempos antigos. Tambem quiz o Kaiser formar uma esquadra formidavel, a maior do mundo, e sustentava que só deste modo evitaria fosse ella engolida por Jonh Bull, perigoso pirata. Ora todas as nações da Europa têm pequenas esquadras, e nenhuma dellas viu seus navios devorados pela culta Albion: a desculpa do imperador era pois pessima. Em sentido contrário, a 26 de Março desse mesmo anno de 1913, a generosa Inglaterra, sempre amiga da paz, propunha que se creasse um Holiday para as construcções navaes, que cessariam, durante um anno, por 
accordo entre todas as potencias mundiaes. Foi o snr. Churchill, ministro da Marinha, quem fez ésta proposta, nesse mesmo anno em que a Allemanha tractava de triplicar o seu thesouro de guerra depositado na torre de Spandau.

A Allemanha começou então sua esquadra de zeppelins, e um delles, qual cavallo de Troya, foi cahir no campo de Marte, em Luneville, com grande extranheza dos officiaes militares franceses, incapazes de comprehender que se tratava de um acto infamissimo de espionagem, serviço em que têm, nesta ultima guerra, adquirido uma triste celebridade as subditos de Guilherme II. Repugnava ao generoso exercito, que mantinha as tradições cavalheirosas de Francisco I. $^{\circ}$, crer que assim procedessem officiaes allemães. Isto em Abril de 1913, e em Março, já a Inglaterra tomava, sensata como é, cautelas contra a espionagem aerea. A França com o seu espirito liberal, luctou, em seu parlamento, com uma formidavel opposição contra o projecto de serviço militar por tres annos. Foi um erro dos deputados de sentimentos liberaes, e deve este erro do grande paiz, patria da liberdade, advertir-nos contra nossa tendencia de nos oppormos aos sacrificios que de nós exija o Governo, mais informado do que nós dos perigos que ameaçam nossa patria. Num governo democratico, onde o militarismo é impossivel, pois é planta que só viça graças ás ambições das casas reinantes, embriagadas pela memoria dos chamados feitos gloriosos dos avós, nas democracias, o povo deve-se prestar, de bom grado, a todos os sacrificios que o Governo pedir sejam feitos pelos cidadãos.

Ahi temos a Allemanha enthesourando dinheiro para a guerra, fortalecendo seu exercito e sua armada, creando uma frota aerea, espiando, preparando-se, em resumo, para o ataque. Por outro lado, o movimento intellectual continuava na rota que traçára Hegel, quando, no começo do seculo XIX, prophetizára o $4 .^{\circ}$ imperio, ou o dominio da Allemanha sobre todo o mundo "Deutschland über alles 
in der Welt", como se diz de norte a sul no imperio do Kaiser, alternando com a canção patriotica de Arndt, proclamando ser alleman toda a terra onde soar a lingua de Schiller. Liszt, no meio do seculo XIX, com a argumentação pseudo-scientifica da predilecção dos allemães, dizia que tudo tendia á união, e que os povos deveriam se unificar tambem. Ultimamente apparecia, causando grande sensação, o livro de Naumann, defendendo a necessidade da formação da "Mittel Europa", ou organização de um imperio central na Europa, sob a direcção do militarismo prussiano. Já, quiçá inspirando-se nestas doutrinas cerebrinas, pois é de referir que os professores exercem dominio mais que desejavel na Allemanha, e mais que desejavel, porque quasi todos são homens de gabinete, eivados de preconceitos de escola, inteiramente ignorantes do que se passa no mundo, já, a esse tempo, se formava no povo a crença de que a expansão alleman deveria ser de Hamburgo a Bagdad, dominada a peninsula balkanica, caminho indispensavel para o sonho dos allemães passar á realidade. Desde 1910, houvera attrictos entre a Russia e a Allemanha, relativamente á construcção da estrada de ferro no Oriente, e mesmo nos Balkans, em Belgrado, haviam-se exaltado os animos contra os austrohungaros. Ora aqui temos como se formava a tempestade na Allemanha.

Ahi estão as nuvens que se accumulavam no hori. zonte da França, além do Rheno, nuvens negras, ameaçadoras, prenunciando proximo temporal. Não ha necessidade de ser sociologo, para, diante da attitude da Allemanha, ver que a guerra ia explodir terrivel, mortifera, conflagrando a Europa inteira, o mundo culto, transformando os campos de cultura em theatro lugubre de carnificina, para vergonha de um povo que se diz culto, e que pretende seguir as normas, os preceitos do Divino Mestre! Mas, si causa horror o modo por que se organizavam as forças que iriam matar, destruir, saquear os bens con- 
quistados, por um longo trabalho, pela sympathica França, é ennojoso o procedimento refalsado com que o Kaiser procurava dissimular seu damnado intento. Em 1911, GuiJherme assistia em Londres á inauguração da estatua de "Victoria, regina, imperatrix", dando mostras de amizade ao rei da Inglaterra. Na abertura do canal de Kiel, mostrava-se affavel, com o occulto intento de illudir as nações sobre seus 'planos imperialistas. Em 1911, ha o incidente de Fez. Surge a Panther nas aguas de Agadir, sendo, mais tarde, substituida pelo cruzador Berlim. E' evidente que fôra uma cartada audaz, pois ninguem será capaz de negar que a Allemanha pretendia fazer de Agadir uma base naval para a sua frota. A França porém teve em Jules Cambon um habil negociador, e as chancellarias do Quay d'Orsay e de Willelmstrasse chegaram a um accordo, de modo a ser desfeita a evidente tempestade, graças a varias concessões feitas pela França á Allemanha. Não foi a França fraca, mas habil, ou antes foi feliz na escolha de seu negociador, que não ficou a dever a Julio Favre e Poyer Quertier, representantes da grande nação em 1870 perante Bismarck. Não pára ahi a dissimulação do Kaiser. Lerei o que se acha no "Correio da Manhan" de 27 de Julho de 1914, ou de poucos dias antes de rebentar a tormenta, de começar a terrivel carnificina que assombra o mundo, como sendo a maior de que ha noticia nos annaes do genero humano. "Londres, 27. - O "Morning Post" publica um telegramma de Petersburgo, dizendo que o imperador Guilherme da Allemanha visitou, secretamente, em Stockolmo, o Presidente da Republica Francesa, o snr. Poincaré, com quem esteve a conversar sobre a crise austro-servia. Accrescenta o despacho que o rei da Allemanha teria promettido ao Presi. dente da França circumscrever o conflicto". Este telegramma, que nunca teve uma séria contestação, é testemunho seguro do machiavellismo do imperador da 
Allemanha: traidor até o momento do bote! Ahi temos os prodromos da conflagração, o prologo desta tremenda tragedia a cuja narração nenhum de nossos posteros deixará de tremer, diante da qual empallidece o que Homero e Virgilio, em epopeas imorredouras, cantaram, tudo quanto de mais horrendo se póde imaginar, hecatombe que faria ver a Dante que, comparado com ella, não passaria seu inferno de um paraiso, lucta que é um opprobrio para a Allemanha, um título de gloria para os alliados, paladinos da civilização christan, ésta civilizaçãc que por mim vos diz, repetindo o verso melodioso do poeta florentino: "Udirai e saprai se m'ha offeso". Dizem os tratadistas da prova que ha indicios anteriores e posteriores ao delicto, e concomitantes com elle. Até aqui vimos os anteriores, e agora passamos aos concomitantes.

Era preciso um pretexto para o lobo atirar-se á sua victima, e elle foi dado, a 28 de Junho, pelo attentado de Serajevo, contra Francisco Fernando. Incidentemente é de vantagem referir o procedimento sinuoso dos allemães intrigando a Servia: foi ésta sempre a arma predilecta dessa gente sem moral. Leiamos o telegramma official de Jovanovitch, enviado logo após o assassinato de Francisco Fernando, porque estamos em uma formação da culpa contra o Kaiser e contra o seu povo. "A hostilidade da opinião publica na Allemanha contra nós dura sempre, entretida por novas mentiras enviadas de Vienna e de Budapest, que quasi todos os jornaes allemães, não obstante nossos desmentidos, espalham com zelo, por intermedio de certos jornaes e agencias". Eis o serviço de diffamação, de traição, que revela o defeito primordial, dominante do caracter allemão, mixto de crueldade e falsia. Não podemos descer a minucias, narrando como procedeu a Allemanha nesta conjuntura, isto é, intrigando, mentindo, lançando a Austria contra a Servia. Só nos cumpre, tomando os pontos capitaes do successo, referir que 
a Austria exigiu da Servia, a quem fingia attribuir a responsabilidade do attentado, actos de satisfação que humilhavam. Foi então que o principe herdeiro Alexandre dirigiu á Russia o telegramma que ficará nos annaes da vida diplomatica do seculo $\mathrm{XX}$, como sendo a mais dolo. rosa pagina, para os corações bem formados. Não ha, ainda nos casos de mais pungente dôr, em Homero, nadı que mais impressione a um leitor cuja alma não esteja empedernida pelo militarismo. Diz o telegramma: "As exigencias da nota austro-hungara são inutilmente humilhantes para a Servia, e incompativeis com a sua dignilade de Estado independente". Vêde bem! Inutilmente humilhantes! Já em Julho de 1914, quando foi expedido esse telegramma, não obstante a dôr que lhe alanceava $o$ coração, observava o principe Alexandre que a Austria pedia coisas que não lhe eram uteis. Para que? Qual a intenção da Austria, formulando exigencias que não lhe eram proveitosas? Esta humilhação inutil, que a Austria sabía dever ser repellida pela Servia, e que, quando não o fosse, nenhuma vantagem traria para a alliada da Allemanha, era o meio de obter que a Russia, protectora da Servia, como diz o principe Alexandre nessa mesma nota, interviesse generosamente em favor da nação offendida, e houvesse a occasião anhelada pela Allemanha e pela Austria para a guerra contra a Russia, e consequentemente contra a França. Vejamos as últimas palavras deste tocante telegramma: "Tivemos o prazo de 48 horas . para acceitar todas as imposições da Austria, e, si não nos curvarmos, a legação austro-hungara deixará Belgrado: . . Não podemos nos defender, e pedimos a V. M. nos dê quanto antes soccorro. A benevolencia preciosa de V. M. que tantas vezes se manifestou em relação a nós, faz-nos esperar que ésta vez ainda, nosso appello será ouvido pelo seu generoso coração slavo". Durante o processo de Serajevo, nota o ministro Jovanovitch, toda a imprensa 
alleman, bem como os jornaes de Vienna, por informações da embaixada alleman, "representavam o processo como sendo negocio que deveria ser liquidado entre a Servia e a Austria eventualmente pelas armas". Os embaixadores da França e da Inglaterra mostraram-se indignados, diz Jovanovitch, quer. com a fórma, quer com o fundo da nota, quer com o prazo fixado, e a julgaram inacceitavel. Havendo a Russia declarado que não podia olhar com indifferença uma humilhação imposta á Servia, o conde de Berchtold, ministro das relaçóes exteriores da Austria, declarou peremptoriamente "que a Austria não renunciaria ás suas exigencias, nem mudaria as condições da nota, e que entendia que a questão não dizia respeito sinão a ella e á Servia, e que nenhum paiz tinha motivos para intervir no assumpto". Ora Tschirsky, embaixador da Allemanha em Vienna' sustentava que "uma liç̧ão devia ser dada á Servia, que a Russia não tinha direito de intervir, e que, quanto á Allemanha, ésta tinha consciencia do que fazia dando apoio á Austria Hungria". Ahi temos, continúa o ministro Jovanovitch,. Tschirsky a sustentar que o que era permittido á Allemanha não o era á Russia. A esse tempo, a Inglaterra tractava de acalmar os animos appellando para um julgamento arbitral. Sir Eduardo Grey, na qualidade de secretario dos negocios exteriores da Inglaterra, diz o "New York Nation" de 6 de Agosto de 1914, propoz ao Imperador da Allemanha que fosse convocado um congresso de potencias para resolver a questão entre a Austria e a Servia. O imperador não acceitou. Eis ahi em rapido esboço o estado da atmosphera nesses dias tempestuosos que precederam de perto ao tremendo morticinio que hoje nos assombra.

Vê-se a reproducção, mais impressionadora porque se tracta da. vida de milhares de homens, vê-se a constante reproducção da fabula do lobo e do cordeiro. A Allemanha não se esquecêra dos conselhos que lhe dera Moltke, 
em 1912: cumpre, no entender do general allemão, surprehender o inimigo, ou antes a victima. Eis suas proprias palavras: "E' necessario deixar de lado os logares communs, sobre a responsabilidade do aggressor.

Quando a guerra se tornar necessaria, cumpre fazel-a, pondo de nosso lado todas as probabilidades de triumpho. Só o bom successo a justifica.

A Allemanha não póde, nem deve deixar á Russia tempo para mobilizar, porque seria ella obrigada a manter, em sua fronteira de Leste, uma força tal, que ficaria em situação sinão de inferioridade, ao menos de igualdade com a da França. Devemos pois começar a guerra sem sermos esperados, para esmagar brutalmente toda resistencia". E' textual, e, ainda que pareça pesada ésta conferencia pelas citações, força é que se veja que todas as nossas accusações se fundam em provas esmagadoras. Mas, dir-nos-ão, não se póde condemnar a Allemanha, sem lhe haver ouvido a defesa. Oh! A fera já falou muitas vezes. O kronprinz declarou que nunca a Allemanha quiz ésta guerrạ, mas accrescentou que seu paiz deveria estar prompto para atacar, pois só assim poderia alcançar seu logar ao sol. E' ésta sua comparação predilecta. Mas si a Allemanha quer, obter, e não conservar, claro é que a Allemanha quer, segundo o proprio kronprinz, a expansão pelas armas, dizia, com o apreciavel bom senso ame. ricano, o "New York Nation", em 1914. Não ha necessidade de se dizer que o kronprinz seja, como é, um homem cruel e sanguinario, ajunta o mesmo jornal, para se reconhecer que elle attribue a seu paiz a tendencia á expansão, ao dominio sobre as outras nações. A verdade entretanto é que, como veremos em outra conferencia, a loucura alleman manifestou-se por varios modos, e entre elles está a mania da perseguição, a mais terrivel obcecação daquelle povo, mania que transluz em todas as palavras do kronprinz. Nunca houve manifestação mais tragica de loucura 
do que quando o Kaiser lançou seu ultimatum á França, exigindo que ella declarasse a attitude que tomaria nas questões que se agitavam na velha Europa, dirigindo logi em seguida, de accôrdo com os brutaes preceitos de Moltke, outro ultimatum, nos mesmos termos, á Inglaterra. Era impossivel que a terra cavalheirosa por excellencia, a brava e generosa França, a França de Eylau, Iena, e Auerstadt, se pudesse curvar sob as ameaças de Guilherme. Cumpria-lhe, porém, não se esquecer da deslealdade de sua inimiga, tendo em memoria que, havendo com a Prussia celebrado, em 1812, um tratado de alliança contri a Russia, foi trahida pelos generaes Bülow e York, que se bandearam com a Russia, tendo ésta traição sido seguida da declaração de guerra á França em 17 de Março de 1813, feita pelo proprio rei da Prussia, Frederico Fuilherme. Foi por isto que, com salutar previdencia, obleve agora o apoio da Inglaterra e da Russia. A fé punica. a dobrez do caracter dos carthaginezes, o desrespeito aos tratados, a traição daquelles cuja cidade foi destruida pelos romanos, achou successores e representantes nos tempos modernos: são os allemães. Eil-os! São ambiciosos, ferozes, mentirosos, não guardam a fé, ferem de surpreza, e, do mesmo modo que os demais criminosos, sempre se dizem innocentes. No crepusculo do seculo passado, e na aurora deste, uma escola de juristas notaveis estudou, com aferro, as multidões criminosas. Hão de, em breve, os sociologos, os que estudam a Psychologia dos povos, estudar, na mesma ordem de idéas, como póde se tornar uma nação criminosa, desprezando o que ha de mais santo sobre a terra: a vida humana, a propriedade e a honra... No tribunal da Historia, sob a accusação das victimas da sanha da Allemanha, ha de comparecer, como ré dos mais atrozes crimes, a geração que hoje empunha armas contra o genero humano, depois de haver preparado friamente o ataque, e, de surpresa, cahido sobre sua 
victima desprevenida, e enganada pelas perfidas mostras de amizade. Não foi sem motivo que disse Napoleão em Santa Helena, quando reflectiu maduramente sobre a politica européa, ter sido grande erro não haver elle esmagado a Prussia, mas, ao contrário, ter deixado generosamente continuar a reinar nella uma casa que sempre foi, e continuaria a ser inimiga da França. Mas, continuemos nesse rapido desenrolar de acontecimentos tenebrosos, e vejamos como procedeu a Allemanha. Violou o Luxemburgo, a Belgica, atacou de surpresa a França, e... (parece que a justiça divina velou pelos destinos humanos) encontra resistencia com que não contava, illudindo-se sobre seu celebre programma de guerra rapida, iniciada de surpresa e a terminar-se immediatamente. A heroica Belgica resiste. A Italia não acompanha a Allemanha, com as justas razóes que vamos ver em seguida. 0 proprio Japão, a cujo Mikado escreveu Guilherme uma carta seductora, intimou a Allemanha a deixar Kiao Tchêo, onde houve a lucta que todos sabemos. Emfim a poderosa Inglaterra collocou-se ao lado da causa da justiça e da humanidade. A marcha dos allemães sobre Paris foi detida pelo potente braço da Providencia, e a cidade da luz escapou das unhas da aguia carniçal que, além do Rheno, a ameaçava com as suas garras aduncas. A traição, mais uma vez, na vida da humanidade, falhava.

Os perfidos descendentes de York e Bülow tinham sido illudidos em suas previsões. Desde então, a guerra não passou de uma serie de ataques de saltedúcres q!ıe pretendem se apoderar das riquezas dos povos vizinliss. Repellidos na Belgica, e em Verdun, detidos na Italia, vencidos no Oriente, continuam os allemães a atacar, usando alternativamente das armas e da intriga. Vejamos outros indicios mais importantes ainda, e formaremos o que se denomina, na sciencia juridica, a evidencia circumstancial. Ninguem, ante as esmagadoras provas que 
vamos produzir, poderá mais, em bôa fé, negar a responsabilidade da Allemanha neste conflicto sangrento, nesta terrivel carnificina. Já vimos que era á Allemanha que convinha a guerra, já mostrámos que era ella que precisava, para satisfazer sua ambição de potencia militar, mover guerra ao mundo, já mostrámos que, dentro della, dominava, sem contraste, um partido que só respirava guerra, vamos agora ouvir testemunhos insuspeitos. Dois factos particularmente constituem prova segura da responsabilidade da Allemanha.

Não vamos mencionar factos que nos levem ainda, com alguma hesitação, a presumir que foi ella a geradora da conflagração européa. Diante do que passamos a narrar, impossivel será um homem de clara intelligencia permanecer em favor da Allemanha. Eis o 1. facto. Andavam os allemães a procurar vulgarizar a crença na America do Norte, de que havia sido a terra de Guilherme que fôra atacada pela França. Uma brochura intitulada "A Verdade", sob a assignatura de Ballin, presidente da Companhia de Navegação Hamburgo America, tinha sido espalhada com prodigalidade. Trazia ainda as assignaturas do principe de Bülow e de muitas notabilidades germanicas. Era particularmente dirigida aos compatriotas de Washington e de Lincoln. $\mathrm{O}$ folheto não produziu o desejado effeito, e o "New Times" de 27 de Setembro de 1914 disse que era um insulto dos allemães aos americanos querer convencel-os de que foram elles os atacados, e que mentir assim aos americanos tinha como consequencia afastar de si a sympathia dos Estados Unidos. Frederico Whitridge, apoiando a opinião desse jornal, accrescentou, na qualidade de homem práctico (e sabido é quanto o são os americanos), que, si a Allemanha se sujeitasse a um jury nos Estados, a não ser nas cidades de Hoboken e Milwakee, onde a maioria é alleman, ouviria sua condemnação como sendo a unica responsavel pelo 
morticinio que assombra a humanidade culta. Indignado com a hypocrisia alleman, accrescentava 'o recto americano: "E' claro a meus olhos, claro quanto a luz meridiana que a violação da neutralidade belga foi a causa da guerra desde muito tempo, e tinha lhe fixado a data com muita approximação, antes que a causa occasional (a questão austro-servia) houvesse precipitado os successos". Agora perguntamos: porque foi que a gente que assignou o celebre manifesto que circulou, por uma ironia, sob o titulo "A Verdade", não acceitou o repto, constituindo o jury, proposto pelo cidadáo norte americano, que, do mesmo modo que os seus compatriotas, é homem que detesta perder tempo, e quer ir logo ao fundo do assumpto de que se occupa? E' que a Allemanha, representada pelos signatarios da brochura, do mesmo modo que os grandes criminosos, temia que, perante o auditorio, na solemnidade tremenda do julgamento, surgissem os espectros lividos dos moços franceses, da aristocracia e dos operarios laboriosos da forte Inglaterra, com seus corpos despedaçados pela metralha assassina, com os cabellos empastados de sangue, hirtos, tragicos, clamando vingança, intimando-os a comparecerem diante do Juiz Supremo, Aquelle que a todos nós ha de julgar!... Passavalhes pelo espirito a sombra de Banquo, tomando o seu assento no festim de Macbeth, e sacudindo sua cabelleira molhada de sangue recentemente derramado. Não vêdes que elles não poderiam supportar essa visão tremenda? Que seria delles no momento em que esses phantasmas erguessem seus braços descarnados, e, apontando os reus, exclamassem: "Nós somos as victimas innocentes da ambição de um monstro, daquelle que mentiu, trahiu, atirou-se de surpresa sobre seus irmãos, obrigou-os a permanecerem nas humidas e immundas trincheiras, suffocou-os com os gazes asphyxiantes, envenenou-os, lançou-os aos campos de batalha moribundos, a servirem de pasto aos corvos 
carniceiros, aos animaes que se nutrem de cadaveres, sujeitou-os a todos os horrores da guerra, só levado pela mais desregrada paixão do mundo.- Maldicto! Małdicto! Maldicto! Mais feroz do que Atila, elle conheceu a doce moral de Christo a que o barbaro era extranho. Nasceu em uma época em que a humanidade já se considerava toda como constituindo uma só familia, ao passo que o barbaro pensava que só para com seu povo tinha deveres. Elle é mil vezes peior do que Attila, do que o vandalo Genserico, de quem um de seus antepassados dizia sentir o sangue nas veias, quando no peito se lhe despertava um intenso desejo de incendiar Roma! E, pallidos, succumbidos, sob a inexoravel e justa accusação, incapazes de articular uma só palavra, para se defender, teriam de ouvir, diante da humanidade, a sentença de morte do seu rei, votado á execração do mundo actual e á da posteridade. Eis porque a Allemanha não acceitou o desafio. O 2. ${ }^{\circ}$ facto é a declaração do sr. Giolitti na Camara Italiana. Disse que recebêra de Di San Giuliano um telegramma do qual destacaremos éstas palavras: "Procuro ligar meus esforços aos da Allemanha, afim de evitar a acção da Austria contra a Servia; mas será quiçá preciso dizer claramente que não consideramos ésta acção eventual como defensiva, e que, por consequencia, não cremos que seja um casus foederis". Ora ahi temos a Allemanha julgada pelos seus alliados, os italianos. Note-se que fala o escol da Italia: falam Giolitti e Di San Giuliano. Ahi está o veredictum de que fugiu a Allemanha nos Estados Unidos, proferido pela Patria do Direito, pela terra onde se formou o Direito privado nos tempos antigos, e onde Alberico Gentile e Pierino Belli da Alba, precursores de Grocio, lançaram os fundamentos do Direito Internacional! A Allemanha já declarou que elle está toło errado; que foi feito pelas nações fracas, e que por isto é contra as fortes; mas que deve ser reformado de accôrdo 
com os interesses dos poderosos. Assim tambem se exprimem os delinquentes em relação ás leis penaes: são, para elles, 'combinações de certos individuos astutos, que se collocam sob a protecção do carcereiro e do algoz, em prejuizo dos fortes, que são os assassinos.

Si estes dois factos não bastarem para a condemnação da Allemanha como sendo a unica responsavel pela conflagração, é que a prova, por mais que se conforme aos principios da Logica, absolutamente nada vale. Ésta que acabamos de apresentar é, sem dúvida, a que todos os mestres consideram como formando a evidencia circumstancial. E assim, com essa iniquidade, atirou-se a fera de Além do Rheno sobre o mundo culto, e iniciou essa apavoradora destruição, de que ha de dar conta á nossa geração e aos posteros. Figuremos, por um esforço de imaginação, o começo da mobilização em França. E' em Agosto. Faz-se a vindima. E' o mez da alegria, tempo de verão, estação dos pobres.

Entra em Astrea o Sol no mez de Agosto.

Baccho das uvas tira o doce mosto.

$\mathrm{Na}$ aldeia ha risos, danças, folgares, amores e alegria. Soam as vozes em canções alegres, acompanhadas das maviosas modulações dos instrumentos rusticos. Chega a noticia da mobilização. $O$ camponez veste a farda e promptifica-se para partir. E' o momento solemne da despedida. A familia o rodeia; e o ultimo adeus é dicto entre lagrimas. A esposa querida, os filhos adorados vêem o pae, o arrimo da familia, partir, talvez para nunca mais voltar. E' a vez derradeira em que seus olhos se fitam no rosto do chefe, que á mulher e aos filhos já parece o semblante do moribundo deixado no campo de batalha, entre os feridos e mortos, desfigurado pelas patas dos cavallos. Quem sabe quantas horas de agonia passará elle, ardendo de sêde, sob um sol abrazador, ou 
engaravitado pelo ar gelado da noite? Quantos dias passará esfaimado, rolando nos trens, semelhante ao animal levado ao matadouro? E será lançado, como si fosse uma fera, contra as hostes de barbaros vindos d'Além Rheno, e será queimado, despedaçado... Oh! Não ha palavras que pintem este momento terrivel, ésta hora tragica, em que a familia vê arrancar-se-lhe um membro, ou antes o proprio coração, mantendo-se-lhe a vida, para sentir e soffrer a tortura que lhe é imposta. O pranto é derramado, e ouvem-se gritos de desespero. Depois... o silencio. A aldeia volta ao socego, ha uma pesada tranquillidade nesta atmosphera de guerra: á alegria geral da vespera succedeu a mais pungente tristeza. Tudo porque u Kaiser, em um momento de ferocidade, derramou sua força sobre o mundo, afim de assenhorear-se do universo, realizando seu sonho de imperio, atacado de uma verdadeira mania de grandeza.

Mas não anticipemos: a loucura do povo allemão, sua ferocidade, sua brutalidade, seu desprezo pelas demais nações serão estudados em ulterior conferencia. Agora tractamos apenas de provar sua responsabilidade pela actual conflagração. Mostrámos que era a elle que aproveitava o crime, pois foi elle que sempre pretendeu dominar, e procurava pretextos para ir conquistar seu logar ao Sol, segundo a pittoresca expressão do kronprinz. Foi elle que augmentou suas forças, sem poder dar explicações do motivo por que adquiria armas indispensaveis para o delicto. Foi elle que, em Agadir, tentou achar uma cecasião para a desejada lucta. Foi elle que interveio na Servia, quando declarava que não era isto licito á Russia. Foi elle que recusou a proposta de um congresso de potencias feita por Sir Eduardo Grey. Foi elle que violou a neutralidade da. Belgica. Foi elle que se lançou, de improviso, sobre sua presa. Não nos é possivel descer a mencionar todas as particularidades que occorreram antes 
e depois de começada a conflagração. E' comtudo digno de referencia que estudos feitos sobre os trabalhos destes ultimos annos da Allemanha, na fronteira, mostram que o plano de viação ferrea obedeceu sempre á idéa de facilitar a invasão da França. O tempo, que lança luz sobre muitas coisas, ha de continuamente accumular provas contra o Kaiser, e é de crer que, dentro em pouco, esteja tão documentada à responsabilidade da Allemanha na actual guerra, quanto hoje está na de 1870 , da qual é o unico responsavel o povo allemão pelo seu chanceller Bismarck, monstro que destruiu maior numero de vidas preciosas que todos os ferozes idolos da antiguidade pagan.

Agora mesmo, discute-se sobre o caso do telegramma que o Kaiser diz ter enviado ao Imperador da Austria, e cuja cópia mostrou ao sr. Gerard, acceitando a mediação européa, uma vez que fosse occupada a cidade de Belgrado, para segurança da Austria. Apparecem ainda mais recentemente as declarações do sr. Morgenthau, embaixador em Constatinopla. Reunem-se, em folhetos, os artigos dos jornaes allemães publicados nos ultimos dias de paz, afim de se tornar paténte que era intenção do Kaiser commetter o delicto por que é hoje accusado. Trazem os zelosos patriotas, defensores dos povos que luctam com a barbaria, á nossa memoria a circumstancia de que o Kaiser queria se aproveitar de estar a Russia nas convulsões determinadas pelas paredes de operarios, a Inglaterra embaraçada com a questão do Home-Rule, e a França absorvida pela questão Caillaux. A Allemanha quiz utilizar-se do momento de embaraço das naçóes cultas, para sobre ellas se lançar de improviso. A leitura de todas essas peças dá a impressão de atrevimento da parte da Allemanha, e de espirito conciliador da parte das demais potencias. A França, a Russia e a Inglaterra fizeram tudo quanto puderam para obter um accôrdo, mas a Allemanha oppoz-se tenazmente a que dessem resultado 
essas louvaveis tentativas. Eis o que occorreu antes de se romperem as hostilidades, segundo vemos nas recentes publicações.

E qual o nosso dever, quando vemos conspurcados os direitos dos povos cultos, quando vemos a Allemanha zombando dos povos fracos, desrespeitando tractados, matando, saqueando, fazendo da guerra systema de governo, cercando viajantes inermes, e hypocritamente dizendo-se protegida pela Divindade, cujas leis despreza, assim como despreza o respeito á palavra dada? A nós, leaes brasileiros, a nós que nunca faltámos á palavra, que respeitámos sempre nossos tractados, que somos amigos de nossos vizinhos, que fomos sempre justos, mesmo em relação a nossos adversarios, a nós, que vemos nosso pavilhão ultrajado pelos submarinos que se emboscaram em nossa passagem, é a nós que corre o triste, mas indiscutivel dever de nos defendermos, de defendermos nossa honra, nossa dignidade de povo livre com as armas nas mãos. Desembainhamos nossa espada quando o Paraguay aprisionou um dos nossos navios, não hesitaremos em marchar contra o audaz allemão que nos insulta em pleno oceano, á face do mundo culto.

Praza aos ceus que breve saibam os barbaros soldados de Guilherme que o sangue dos heroes que conquistaram a India ainda estua, tão quente quanto no seculo XVI, em nossas arterias. Saiba Guilherme que nossa patria é semelhante á tunica inconsutil do Salvador: só depois de trahidos e sacrificados, perderemos nossa terra, mas a perderemos inteira, perdendo nossa vida, nosso posto entre as nações soberanas, mas para a conquistar, terá a Allemanha de passar por sobre o cadaver do último dos brasileiros, pois nunca será retalhada a patria brasileira.

Braz de Sousa Arruda, Docente da Faculdade. 